\title{
Economical aspects of water-mist assisted air- cooled chillers usage in the temperate climate
}

\author{
Arturs Brahmanis ${ }^{1 *}$, Anatolijs Borodinecs ${ }^{2}$, Jelena Tihana ${ }^{2}$, Jurgis Zemitis ${ }^{2}$ and Daria \\ Monastyreva $^{3}$ \\ ${ }^{1}$ LTD LAFIVENTS, Riga, Latvia \\ ${ }^{2}$ Riga Technical University, Kipslas street 6B/6A, Riga, Latvia \\ ${ }^{3}$ Peter the Great St. Petersburg Polytechnic University, Polytechnicheskaya 29, St. Petersburg, \\ 195251, Russian Federation
}

\begin{abstract}
The prices for energy resources, global trends for greenhouse gases emission limitation makes the application of higher efficient chillers with process air evaporative cooling more common. In order to determine the economical feasibility for choosing the particular type of cooling unit for the specific building, many factors should be taken into account, which are not always available. One of these factors is the European seasonal energy efficiency ratio (ESEER) defined by the Eurovent Certification Company. It overtakes the outdoor air temperatures from $+20^{\circ}$ to $+35^{\circ} \mathrm{C}$ with different cooling loads, which is not completely suitable for the Baltic States. Within the research monitoring of cooling system and air parameters was performed during the cooling season. It was indicated that the distribution of the energy generated by the investigated object differs significantly from the distribution of influence factors according to ESEER test methodology. The calculation of the annual energy consumption for the particular historic building according to the recorded power distribution within the outdoor air temperature ranges was performed. Using the proposed method the results are much closer to the actual annual energy consumption of the cooling plant than the one performed using the seasonal efficiency with the base temperature of $18^{\circ} \mathrm{C}$.
\end{abstract}

\section{Introduction}

Nowadays cooling has become a significant part of modern building's energy consumption. The new trend is so called solar cooling and night cooling systems. While the night cooling can be used in apartment buildings, the mechanical cooling is a vital part for office buildings including also such unclassified buildings as police departments, university campuses and military campuses. In many cases air-condition systems are also installed in existing buildings during the refurbishment. In these cases, the energy efficiency and reduction of energy consumption is not the only factor determining what type of HVAC system to choose. Another key factor is the available power capacity of existing electricity grid connection. For both before mentioned reasons the application of more efficient chillers with process air

\footnotetext{
*Corresponding author: anatolijs.borodinecs@ rtu.lv
} 
indirect evaporative cooling (IEC) can insure increased energy efficient operation and possibility to keep existing connection to the power grid, even in the temperate climate of Baltic States.

Despite the numerous benefits of such innovative solutions, their implementation can be costly. The justification of profitability and economic issues are confronted by every engineer-innovator. The solution to this problem was presented by the scientific team from Peter the Great St. Petersburg Polytechnic University. The application of the developed mathematical model when investing in energy-saving solutions allows to take into account all the variety of factors. Also from the results of the article, future investors can find out at what points they should pay attention to reduce the payback period. [1]

Study results confirm a major potential for the generation of cooling water, which can be used to provide effective cooling of modern buildings by means of contemporary water based sensible cooling systems, such as fan coils and chilled ceiling panels and beams. [2]. Results of other authors shows that AD-IEC cooling technology allows to improve chiller efficiency up to $0.6 \mathrm{~kW} /$ Rton. [3]. In addition to indirect evaporative cooling have been proved sustainability of adsorption cooling which has still a plenty of opportunity for future investigation and wide implementation for energy efficient and environmental friendly HVAC systems. [4-6]. The evaporative cooling dependence on the weather condition enforces limitations on its applicability. One of the methods to use the adiabatic effect to increase energy efficiency of the cooling system is to use it with combination with compressor - refrigerant system. It was reported that the annual energy consumption can be reduced by $10.9 \%$ for a commercial building [7] and about 14\% EER and 6\% air-cooled chillers' cooling capacity increase, when using chillers with water mist-assisted condensers [8-9]. In addition, evaluations showed the effect of water mist system on the energy efficiency of air-cooled chillers. Results have shown that application of water mist generation rate allows to increase the COP by up to $21.3 \%$. [10-13]. Recent study also highline efficiency of evaporative cooling, stating the performance of evaporative cooling is up to $82 \%$ better that for the conventional air-cooled chillers [14].

As at now IEC - vapour compression combined chillers, have been used in the Baltic States quite rarely, particularly in projects with co-financing on the green energy usage. The main factors for choosing one or another type of cooling equipment are climate, cost efficiency, sizes, and availability of external recourses, such as spare heat energy, or the proximity of water sources.

Often it is necessary for engineers and developers to perform rather precise and accurate economic calculations on the payback period in order to justify their choice of the certain piece of equipment. However, data available on the effectiveness of chillers at a partial load and on the power distribution at ambient temperatures during the cooling season is not sufficient. The basis of modern methods of calculation is the concept of "typical year", which makes the estimation of the outdoor climate quite rough. An alternative new method is generating climate data arrays programmatically with a number of pseudorandom number generator [15]. Using it at the design stage, it is possible to make more cost-effective solutions due to the rational setting of initial conditions. The use of such probabilistic methods, devoid of the drawbacks of classical ones, opens broad prospects for the improvement of various engineering systems.

The rate of studying the energy efficiency of cooling systems should be increased. Experience and knowledge greatly exceed in related areas. For example, a lot of works are devoted to the effectiveness of facade solutions. The work about ventilated facade integrated with the HVAC system for cold climate describes the mathematical modeling of convective heat flow in ventilated facades without mechanical draft [16]. Among the advantages of energy-efficient solutions, the authors believe that it is necessary to reduce the pressure on 
the environment, to improve the comfort of the building and to reduce operating costs. Another work, which is written by the team from Peter the Great St. Petersburg Polytechnic University is about ventilated facades under extreme climate conditions [17]. In unique climatic conditions, the use of effective solutions not only gives the previously mentioned advantages, but also makes fundamental changes in the strength properties of structures. The experience and methods can be applied in the development of the air-cooling systems.

The very interesting work is about the calculation of heat energy consumption, which directly relates to ventilation and air conditioning systems [18]. Examining a typical historical building with a courtyard, the authors propose innovative solutions, including reducing energy supply costs. Fitting of a new structural element, a glass dome, also affects cooling calculations, reducing the load on the system.

Useful experience can be gained from the work dedicated to the periodic mode of heating of the building [19]. This method allows to determine the time which it is possible to turn off heating during the non-working period with maintenance required temperature condition in working period. Similarly, considering the temperature distribution in an enclosure structure and warming velocity of assorted designs of enclosure structures, it is possible to reduce energy loses for cooling by performing the optimum choice of periodic schedules of chill [22-23].

Thus, there are many works devoted to energy efficiency. However, there is still no generally accepted methodology for choosing the particular type of cooling unit for the specific building. Taking the foregoing into consideration, let us formulate the purpose and objectives of the research.

The purpose of this study is substantiation of the new method for choosing water-mist assisted air-cooled chillers.

It can be done by achieving the following objectives:

1. calculation of the seasonal energy consumption

2. calculation of the economic feasibility

\section{Methods}

\subsection{Overall description}

Research was performed in two stages: practical measurement and laboratory experiment. As a pilot of this work recently restored building of the Art Museum Riga Bourse, which was initially built in the middle of 19th century. Nowadays it was reconstructed and opened in August 2011.

In order to assess the combined cycle freon - indirect evaporative water cooling equipment operating efficiency greater diapason tag, was performed a series of experiments. Studies conducted using the Riga Technical University, Faculty of Civil Engineering HGWT energy laboratory. Experiments carried out in two stages: during the summer period when operating the plant operated at a constant cooling demand simulated; in the fall, when the plant was operated at variable cooling loads simulated. The heat load of the equipment provided by the electric flow-through water heater with a nominal power Qel. $=24 \mathrm{~kW}$. In order to ensure that the consumption of existing hydraulic circuit was modified by connecting cooling and heating circuits. Laboratory equipment is shown schematically in Figure 1. 


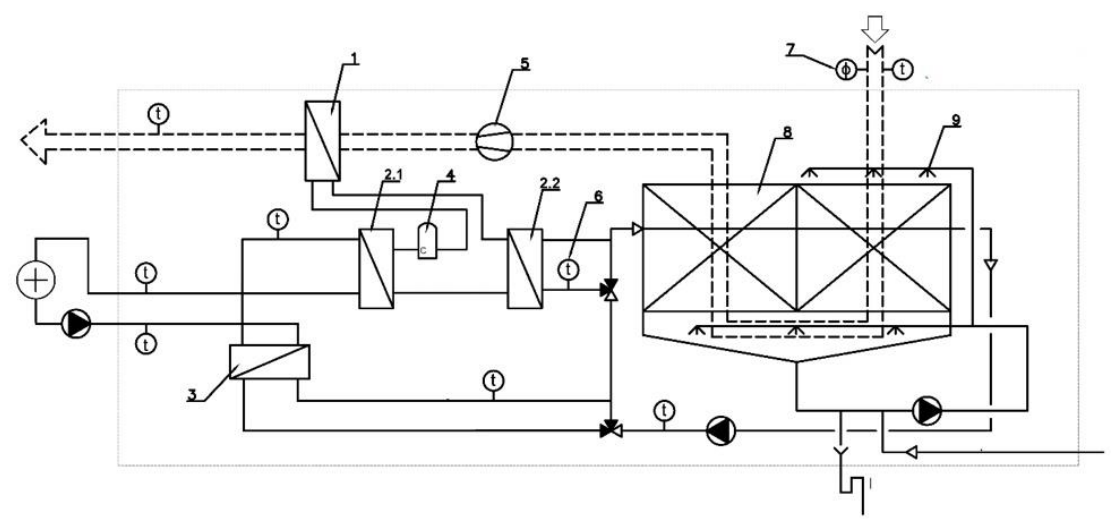

Fig. 1. Laboratory test units

Cooling devices are key components of the water - air heat exchanger with water spray nozzles, circulation pumps, water - water and water - freon heat exchangers, centrifugal fan with frequency converter, air condenser and compressor. Laboratory equipment data set out in Table 3.1:

Table 1. Laboratory equipments' technical data.

\begin{tabular}{|l|c|l|c|}
\hline $\begin{array}{l}\text { Nominal inlet air flow, } \\
\mathrm{m}^{3} / \mathrm{h}\end{array}$ & 4400 & $\begin{array}{l}\text { "adiabatic" loop pump } \\
\text { power, } \mathrm{kW}\end{array}$ & $2 \mathrm{x} 0.64$ \\
\hline Fan power, $\mathrm{kW}$ & 2.13 & $\begin{array}{l}\text { Pump power at secondary } \\
\text { loop, } \mathrm{kW}\end{array}$ & 0.44 \\
\hline $\begin{array}{l}\text { Water - Water heat } \\
\text { exchanger, type }\end{array}$ & GBS700M-40 & $\begin{array}{l}\text { Secondary loop condenser } \\
\text { pump power, } \mathrm{kW}\end{array}$ & 0.44 \\
\hline $\begin{array}{l}\text { Chilled water flow, } \\
\mathrm{m}^{3} / \mathrm{h}\end{array}$ & 3.0 & Compressor el. power, $\mathrm{kW}$ & 17.9 \\
\hline
\end{tabular}

Laboratory equipment is equipped with a plate "adiabatic" water - air heat exchanger with water spray nozzles, air intake. The heat exchanger is a double i.e. cooled water flow wetted working air passes through twice, cross (cross-flow) direction. The plates are made of polypropylene and has a ribbed side of the water, creating a square cross-section of water channels.

\subsection{Payback period calculation}

The calculation of the payback period is performed by comparing the financial costs over the lifetime of the proposed project with the main / base case. For the reliable calculation of financial costs, the following data is necessary: capital (initial) investment, including the cost of equipment, together with all the necessary arrangements for its installation (strengthening of structures, occupied capacity of the building, electrical cabling, water / sewer supply, etc.), climate data for the particular area where the project is implemented, the cost of electric energy (and heat energy in the case of sorption chillers), the cost of water / sewer supply, and service costs.

The simplified calculation can be executed by using a seasonal energy efficiency index ESEER, and the average number cooling hours CDH (cooling degree hours). The simplified algorithm for payback period calculation for the particular equipment is described below in the Figure 2. 


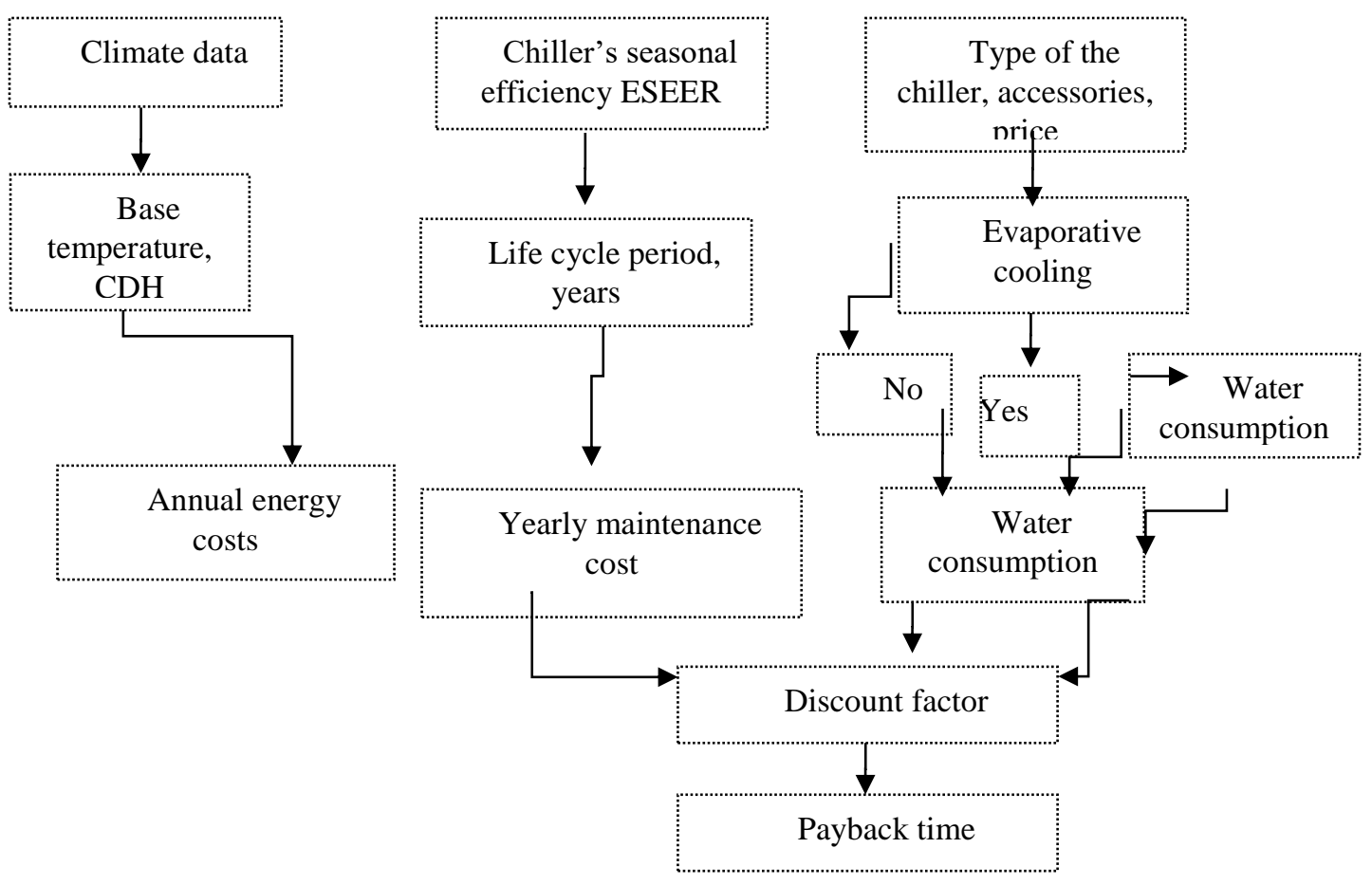

Fig. 2. The simplified algorithm for the payback period calculation

\section{The distribution of the cooling load}

For a more accurate calculation of the annual energy consumption of the cooling unit it is necessary to find out the efficiency of a particular chiller at the various loads and temperatures of the process air. The information on the anticipated cooling capacity in different air temperatures is also necessary. It should be noted that the last parameter stated changes due to individual characteristics of the building / site, which depend on its location, the thermophysical characteristics of the isolating constructions, the surface and characteristics of the glazing, thermal inertia and internal heat gains. This information can be obtained by thermal simulations in specialized programs, or in an experimental way within the existing buildings / objects.

In order to specify the distribution of the cooling load within outdoor temperature range in a historic building in a climate of Latvia, the monitoring of the system parameters and the parameters of the cooling air within the cooling period was performed.

The investigated system is located in recently restored building of the Art Museum Riga Bourse, which was initially built in the middle of 19th century. Nowadays it was reconstructed and opened in August 2011. The building's HVAC system is equipped with combined IEC - vapour compression liquid chiller. From 4745 hour-long cooling period (the period was determined by the cooling demand calculations), which was recorded in minutes, the average produced cooling capacity within 1 hour was calculated, afterwards the data was ranged according to the temperature. The calculated cooling capacity output depending on the outdoor air temperature is displayed on Figure 3 below. 


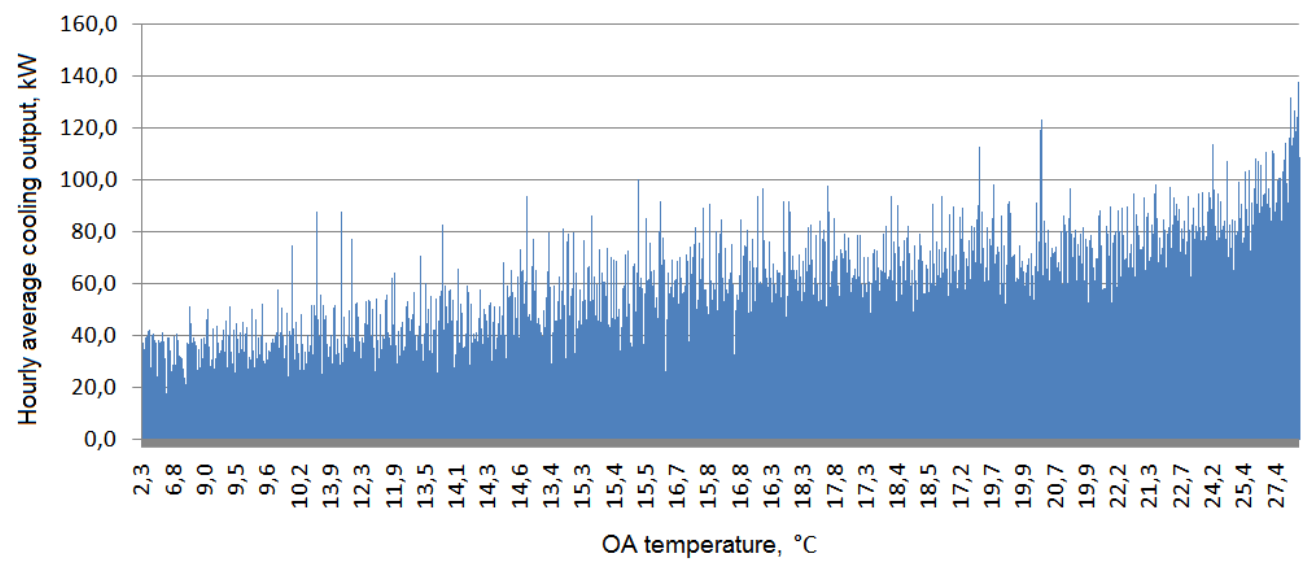

Fig. 3. Cooling capacity within outdoor air temperatures

From the Figure 2 displayed above, authors conclude, that the cooling energy during the cooling season was produced in the temperature range from 2 to $28^{\circ} \mathrm{C}$. It should be reminded, that within the ESEER test procedure seasonal energy efficiency ratio of the particular equipment is determined by reflecting its EER within the four different load levels and working temperatures. Authors want to highlight that this is a good index for cooling effectiveness assessment within the different weather conditions. Seasonal energy efficiency, in accordance with EN14511: 3-2011 and research studies [20] is calculated according to the equitation (1) explained below:

$$
E S E E R=A \times E E R_{A}+B \times E E R_{B}+C \times E E R_{C}+D \times E E R_{D}
$$

Which components are described in details in Table 2 below:

Table 2: ESEER components description

\begin{tabular}{|c|c|c|c|c|}
\hline Conditions & $\begin{array}{r}\text { Load } \\
\text { ratio, \% }\end{array}$ & $\begin{array}{c}\text { Weighing } \\
\text { coefficient }\end{array}$ & $\begin{array}{c}\text { Air temperature } \\
\text { at condenser inlet } \\
\text { (air cooled } \\
\text { chillers) }\end{array}$ & $\begin{array}{c}\text { Water } \\
\text { temperature at } \\
\text { condenser inlet } \\
\text { (water cooled } \\
\text { chillers) }\end{array}$ \\
\hline A & 100 & 0.03 & 35 & 30 \\
B & 75 & 0.33 & 30 & 26 \\
C & 50 & 0.41 & 25 & 22 \\
D & 25 & 0.23 & 20 & 18 \\
\hline
\end{tabular}

In authors opinion ESEER introduction is a great achievement within the equipment assessment principles, which is likely to reflect more accurately the effectiveness in case of Central Europe or the Mediterranean part of Europe. On the other hand, when in Latvian climate conditions the building cooling load is traditionally calculated using an outdoor air temperature of $+27^{\circ} \mathrm{C}$ (Riga), ESEER test parameters are quite distant from the real situation. Experience shows that the cooling demand in many objects occurs at much lower outdoor temperatures such as $+15^{\circ} \mathrm{C}$ or even $+10^{\circ} \mathrm{C}$. Such objects may include: office premises with large amount of office equipment, facilities with high human density, retail space with great light intensity, and rooms with large windows surfaces and no shadings. Since the location of ventilation diffusers does not always provide cooling in the most comfortable way for people in the premises, air cooling in such cases is carried out with chillers and the room temperature is adjusted. 
The ESEER calculation methodology displayed within the Table 1 and Formula 1 is based on EER values within the four cooling loads, where each part of this amount is multiplied by the impact factor, which determines the usage frequency of a given cooling load.

The value of summed $\mathrm{kWh}$ produced at a certain temperature range with a step of $2.0^{\circ} \mathrm{C}$ is presented on Figure 4. According to the performed estimates the vast majority or about $67 \%$ of cooling energy during the cooling period was produced when the outside temperature was in the range from 10 to $20^{\circ} \mathrm{C}$. According to the generally accepted practice, the cooling is required when $\mathrm{T}_{\mathrm{OA}}$ is higher than $18-19^{\circ} \mathrm{C}$, (which is also generally accepted base temperature for cooling degree-hour calculation). Within the particular building non-weather dependent cooling accounts for more than half of the total annual cooling energy. This characterizes the objects with high heat discharge, and / or high microclimate requirements. In other sources, a number of energy efficiency project analysis pointed to a large inaccuracy in heating / cooling system energy savings estimates, if they are performed only based on the weather data. [21].

The portion of cooling energy at $\mathrm{T}_{\mathrm{OA}}$ less than $10^{\circ} \mathrm{C}$, which was produced at the investigated site during the cooling season accounted for $5.9 \%$ of the total energy produced. This part of the calculation is added to the calculation due to the equipment operating efficiency drawbacks within this range.

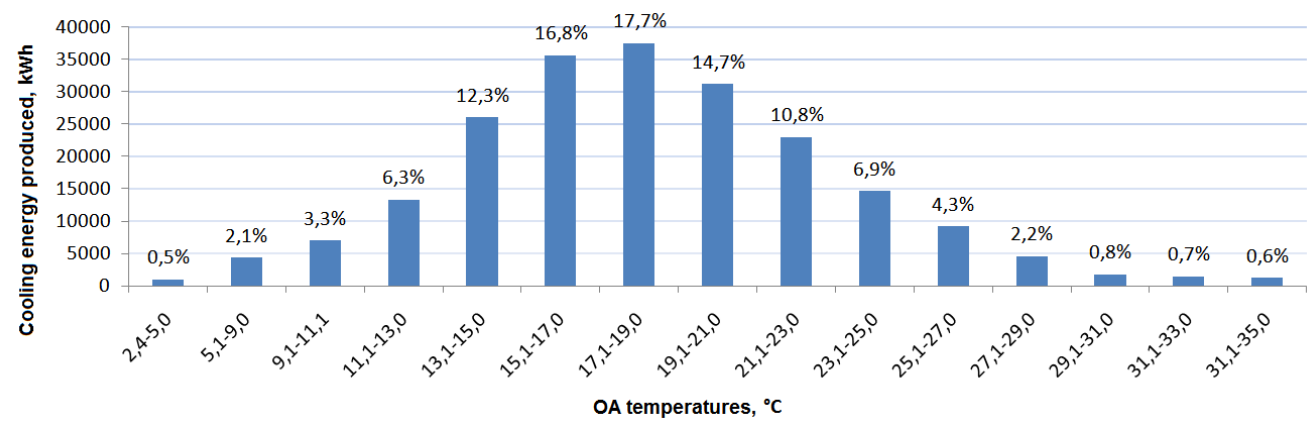

Fig.4. Cooling energy produced at $\mathrm{T}_{\mathrm{OA}}$ diapasons

ESEER impact factors at the same outdoor (condenser inlet) temperature distribution for comparison are shown in Figure 4 below.

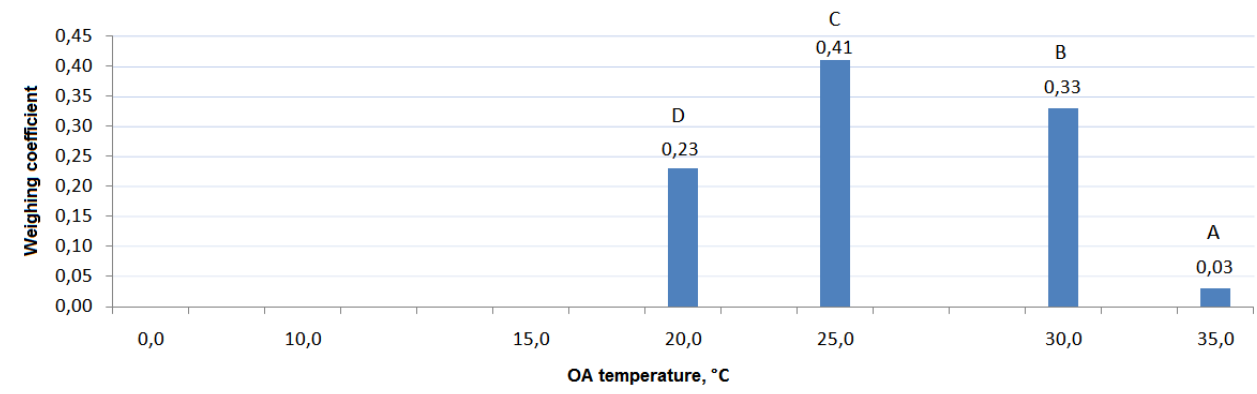

Fig. 5. ESEER weighing coefficients at inlet air temperatures

As can be seen from the Figures 4 and 5 above, generated capacity, meaning the outdoor air temperature distribution within the building / object, is very different from ESEER impact factors, which means that the ESEER index application to the energy calculations within the Latvian cool climate will provide very approximate results. In order to determine the results gap for chiller energy consumption calculations, the comparison calculations were performed using the ESEER testing defined parameter values, and using the adjusted parameters 
obtained on the construction object in accordance with the recorded data. Seasonal electricity consumption was calculated using the Equitation (2) explained below:

$$
Q_{\text {el.seas. }}=\sum_{\Delta T_{n}}\left(\frac{Q_{\text {c.nom. }}}{E E R_{\Delta T_{n}}} * C L_{\Delta T_{n}} * D H_{\Delta T_{n}}\right)+Q_{\text {el.std }}
$$

where: $Q_{\text {el.seas. }}=$ seasonal electric energy consumption, $\mathrm{kWh} ; \Delta T_{n}=$ outdoor temperature interval; $E E R=$ energy efficiency ratio within temperature interval / cooling load; $Q_{c \text {.nom. }}=$ nominal cooling power, $\mathrm{kW} ; C L=$ cooling load, $\%$ of nominal cooling power; $\mathrm{DH}=$ cooling degree hours within the temperature interval, $h$.

Energy efficiency ratio of the combined chiller (KKCD) and conventional vapour compression chiller (KCD) was taken from technical data in ESEER diapason. The data in temperatures $10-20^{\circ} \mathrm{C}$ was assumed for the $\mathrm{KCD}$, and taken from the series of laboratory experiments for $\mathrm{KKCD}$. The EER data used within temperature intervals at $16 / 20^{\circ} \mathrm{C}$ system temperatures shown in Figure 6.

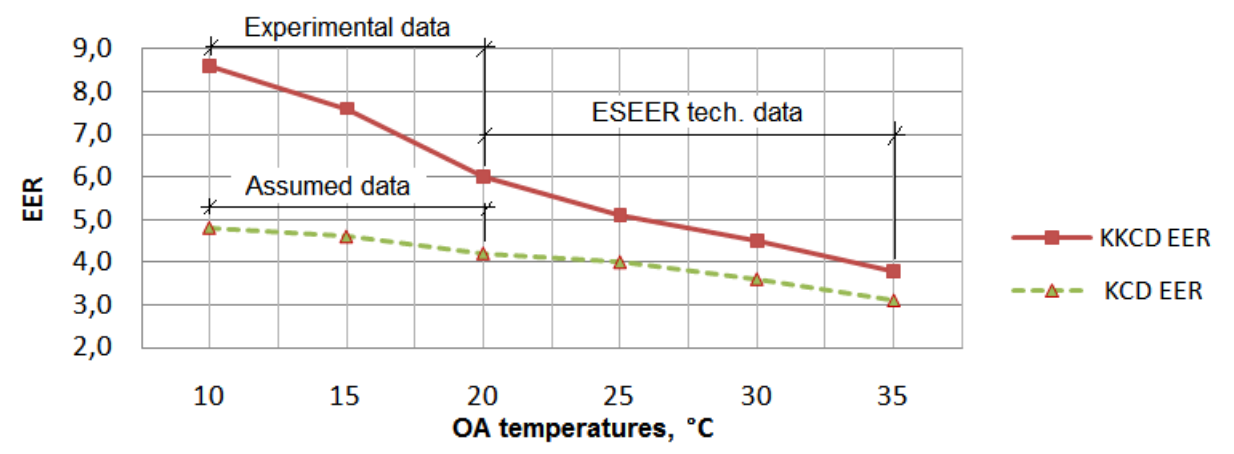

Fig.6. EER at $16 / 20^{\circ} \mathrm{C}$ system temperatures for $\mathrm{KCD}$ and $\mathrm{KKCD}$ units

\section{Results}

For the case of using ESEER calculations were performed using the base temperature (TB) $18^{\circ} \mathrm{C}$ for the chiller with nominal cooling power Qc.nom. $=400 \mathrm{~kW}$ at $16 / 18^{\circ} \mathrm{C}$ system temperatures. Number of CDH from Latvian Typical reference year were grouped together according to the steps of the temperature, meaning the ESEER power tests, efficiency and electric power were taken from the technical information of producers. The calculation results for energy consumption are displayed in Table 3 below.

Table 3. Results of energy consumption calculation at $\mathrm{T}_{\mathrm{B}}=18^{\circ} \mathrm{C}$

\begin{tabular}{|c|c|c|c|c|c|c|c|c|}
\hline \multirow{2}{*}{ ن̃ } & \multirow{2}{*}{$\begin{array}{c}\mathrm{T}_{\mathrm{OA}} \\
\text { diapaso } \\
\mathrm{n},{ }^{\circ} \mathrm{C}\end{array}$} & \multirow{2}{*}{$\begin{array}{c}\mathrm{CD} \\
\mathrm{H}\end{array}$} & \multirow{2}{*}{$\begin{array}{l}\text { Load } \\
\text { ratio, \% }\end{array}$} & \multirow{2}{*}{$\begin{array}{l}\text { KKC } \\
\text { D } \\
\text { EER }\end{array}$} & \multirow{2}{*}{$\begin{array}{l}\text { KCD } \\
\text { EER }\end{array}$} & \multicolumn{2}{|c|}{$\begin{array}{c}\text { Yearly electrical } \\
\text { energy consumption, } \\
\mathrm{kWh}\end{array}$} & \multirow{2}{*}{$\begin{array}{l}\text { Yearly } \\
\text { electrical } \\
\text { energy } \\
\text { economy, } \\
\text { kWh }\end{array}$} \\
\hline & & & & & & KKCD & $\mathrm{KCD}$ & \\
\hline A & $33-37$ & 2 & $100 \%$ & 3.6 & 2.7 & 178 & 237 & 59 \\
\hline $\mathrm{B}$ & $28-32$ & 24 & $75 \%$ & 4.2 & 3.4 & 1371 & 1694 & 323 \\
\hline $\mathrm{C}$ & $23-27$ & 288 & $50 \%$ & 5.1 & 4 & 9035 & 11520 & 2485 \\
\hline \multirow[t]{2}{*}{$\mathrm{D}$} & $18-22$ & 965 & $25 \%$ & 5.7 & 4.2 & 13544 & 18381 & 4837 \\
\hline & & & & & Total & 24128 & 31832 & 7704 \\
\hline
\end{tabular}


Further calculation according to the Formula (2), taking a base temperature of $+10^{\circ} \mathrm{C}$, was performed. Consumed energy in the range from $0^{\circ}$ to $10^{\circ} \mathrm{C}$ was assumed at a rate of $5.9 \%$, according to measurements on site (Table 4).

Table 4: Results of energy consumption calculation using expanded data

\begin{tabular}{|c|c|c|c|c|c|c|c|}
\hline \multirow{2}{*}{$\begin{array}{c}\text { ToA } \\
\text { diapason } \\
,{ }^{\circ} \mathrm{C}\end{array}$} & \multirow[t]{2}{*}{$\mathrm{CDH}$} & \multirow{2}{*}{$\begin{array}{c}\text { Load } \\
\text { ratio, \% }\end{array}$} & \multirow{2}{*}{$\begin{array}{l}\text { KKCD } \\
\text { EER }\end{array}$} & \multirow{2}{*}{$\begin{array}{l}\text { KCD } \\
\text { EER }\end{array}$} & \multicolumn{2}{|c|}{$\begin{array}{l}\text { Yearly electrical } \\
\text { energy } \\
\text { consumption, } \mathrm{kWh}\end{array}$} & \multirow{2}{*}{$\begin{array}{l}\text { Yearly } \\
\text { electrical } \\
\text { energy } \\
\text { economy, } \\
\text { kWh }\end{array}$} \\
\hline & & & & & $\mathrm{KKCD}$ & $\mathrm{KCD}$ & \\
\hline $27-33$ & 49 & $90 \%$ & 4.2 & 3.3 & 3360 & 4276 & 916 \\
\hline $24-26$ & 150 & $75 \%$ & 5.1 & 4.0 & 7059 & 9000 & 1941 \\
\hline $20-23$ & 580 & $50 \%$ & 5.7 & 4.1 & 16281 & 22634 & 6353 \\
\hline $17-19$ & 804 & $30 \%$ & 6.0 & 4.2 & 12864 & 18377 & 5513 \\
\hline $14-16$ & 964 & $15 \%$ & 6.3 & 4.3 & 7345 & 10761 & 3416 \\
\hline $10-13$ & 1276 & $10 \%$ & 7.0 & 4.5 & 5833 & 9074 & 3241 \\
\hline $0-10$ & \multicolumn{4}{|c|}{$5.9 \%$ of the overall $\mathrm{kWh}$ consumed } & 3112 & 4373 & 1261 \\
\hline
\end{tabular}

As it can be observed from the Table 3 , results both in $\mathrm{kWh}$ consumed and the total gross energy savings for the use of both chillers in the first and second calculation differ significantly, due to the cooling hours ( $\mathrm{CDH} 3823$ with a base temp. $10^{\circ} \mathrm{C}$ ), which in the second case is about three times more than in the first case (CDH 1279 with a base temp. $\left.18^{\circ} \mathrm{C}\right)$.

Payback time calculations were performed assuming discount rate 5\%, and maintenance cost average for local market. The discount factor for each year of operation calculated by:

$$
d_{f}=\frac{1}{(1+p)^{n}}
$$

where: $d_{f}=$ discont factor; $p=$ discount coefficient, $\% ; n=$ payment year, in reference to the base year. Net present value cash flow determine the present value, discounted necessary to return the curve by the following expression:

$$
T T V(\text { projektam })=A_{o}+\sum_{t=1}^{n} \frac{F_{t}}{\left(1+k+p_{t}\right)^{t}},
$$

where: $F_{t}=$ Net present value in time period $t ; k=$ payback rate; $A_{o}=$ Initial cost

Any additional costs, e.g. water supply and plumbing pipes in case of IEC chiller, or roof stronger construction for KCD or dry-cooler hasn't been evaluated. Payback calculations of combined ductable IEC chiller KKCD showed, that compared to standard packaged roof mounted KCD chiller the payback period is longer than 20 years, because of big (approx. two times) price difference between those units. Other calculation performed in comparison to Chiller - Dry cooler system, including hydro module and circulation pump. In this case the payback time of KKCD chiller is 8 years, which means that the use of combined unit is profitable in that case.

\section{Conclusions}

Within the research monitoring of air cooling system parameters and air parameters was performed during the cooling season. It was indicated that the distribution of the energy generated by the investigated object differs significantly from the distribution of influence factors according to ESEER test methodology. The calculation of the annual energy consumption for a particular historic building according to the recorded power distribution within the temperature ranges was performed. Authors highlight that the calculation result 
performed using the proposed method is much closer to the actual annual energy consumption of the particular equipment than the one performed using the seasonal efficiency with the base temperature of $18^{\circ} \mathrm{C}$.

In order to facilitate the economic calculations in a temperate climate of the Baltic States, it is recommended to perform the similar studies for the other types of buildings. It is also necessary to extend the range of temperature data for process air / cooling output / efficiency of cooling equipment provided by the suppliers. Both these factors could make annual energy consumption and economic calculations easier and much more precise than these are at the present.

\section{Acknowledgements}

This study was supported by European Regional Development Fund project Nr.1.1.1.1/16/A/048 "Nearly Energy Solution for unclassified buildings".

\section{References}

1. A.S. Gorshkov, N.I. Vatin, P.P. Rymkevich, O.O. Kydrevich, MCE, 78, 65-75 (2018)

2. B. Costelloe, D. Finn,. E and B, 35, 573-591, (2003)

3. A. Brahmanis, G. Frīdenbergs, V. Borisova, SCANVAC International Conference on Air Distribution, 13, 401-407 (2014).

4. A. Sapienz, I. Velte, I. Girnik, A. Frazzica, G. Füldner, L. Schnabel, Y. Aristov., R E., 110, 40- 46 (2017)

5. S. Santamaria, A. Sapienza, A. Frazzica, A. Freni, I. S. Girnik, Y.I. Aristov., A E, 134, 11-19, (2014)

6. Y. I. Aristov., A T E, 31, 537-544, (2011)

7. F.W. Yu, K.T. Chan, A T E, 31, 537 - 544, (2011)

8. B. Casvendi, U. Calli, A. Hebpasli. Proceedings of Clima, 60-68 (2010)

9. O. J. Seung, K. Choon, T. Kyaw, C. Wongee, C. E. J. Kian., E and B., 127, 183-193 (2016)

10. K.T. Chan, J. Yang, F.W. Yu. Proceedings of Building Simulation, 2088-2095, (2011)

11. J. Yang, K.T. Chana, X.Wu, F.W. Yu, X.Yang. E and B, 55, 273-284, (2012)

12. F.W. Yu, W.T. Ho, K.T. Chan, R.K.Y. Sit, J. Yang. I J R, 73, 54-64, (2017)

13. F.W. Yu, K.T. Chan, A T E, 31, 537 - 544, (2011)

14. A.E. Kabeel, Y.A.F. El-Samadony, M.H. Khiera. A T E , 122, 204-213, (2017)

15. O.D. Samarin, MCE, 73, 62-69 (2017)

16. M.R. Petritchenko, E.V. Kotov, D.V. Nemova, D.S. Tarasova, V.V. Sergeev, MCE, 77, 47-58 (2018)

17. M.R. Petritchenko, E.V. Kotov, D.V. Nemova, D.S. Tarasova, V.V. Sergeev, MCE, 77, 130-140 (2018)

18. A. Gorshkov, V. Murgul, EMMFT, 692, 577-591 (2017)

19. D.S. Tarasova, M.R. Petrichenko, MCE, 72, 28-35 (2017)

20. S. Marinhas, R J, 31-33, (2013)

21. R.C. Sonderegger, A Baseline, ASHRAE Summer Meeting Proceedings, 18-25, (1998)

22. A. Nikonorov, V. Terleev, S. Pavlov, I. Togo, Y. Volkova, T. Makarova, V. Garmanov, D. Shishov, W. Mirschel Procedia Engineer., 165, 1741-1747. (2016)

23. A.E. Bolotin, V.V. Bakayev, S.A. Vazhenin, Journal of Physical Education and Sport, 15 (2015) 